\title{
Gaseous Exchange and Acid-Base Balance in Premature Lambs during Liquid Ventilation since Birth
}

\author{
THOMAS H. SHAFFER, ${ }^{(32)}$ DAVID RUBENSTEIN, GORDON D. MOSKOWITZ, AND MARIA \\ DELIVORIA-PAPADOPOULOS \\ Departments of Physiology, Medicine, and Pediatrics, School of Medicine, University of Pennsylvania, \\ Philadelphia, Pennsylvania, USA
}

\begin{abstract}
Extract
Nine distressed premature lambs were studied before, during, and after ventilation with fluorocarbon liquid (FC-80). It was found that premature lambs, delivered by cesarean section, could be adequately ventilated with oxygenated liquid for periods up to $3 \mathrm{hr}$. Using fluarocarbon liquid in conjunction with the described liquid breathing system, it was possible to maintain remarkably good pulmonary gas exchange and acid-base balance during normothermic conditions. In addition, peak intratracheal pressures measured during recovery from liquid ventilation were significantly reduced $(P<0.001)$ as compared with preliquid ventilation values. This improvement in lung function is in direct contrast to the deterioration in that of the adult animal following liquid ventilation as reported previously.
\end{abstract}

\section{Speculation}

Although an enormous amount of studies remain to be performed, at this time it is appealing to speculate about the possibilities of this therapeutic modality in the preterm human neonate with respiratory. distress. We cannot help but think that this method of therapy serves a twofold purpose: (1) maintenance of infants with lungs too stiff to ventilate with gas, and (2) a treatment for reducing surface-active forces in infants with marginal lung stability.

Liquid ventilation in mammalian species has been studied by various intestigators since 1958 (12). More recently, fluorocarbon liquids capable of dissolving larger volumes of respiratory gases at atmospheric pressure $(3,10,14,17,22,24)$ were recognized as useful media for conducting oxygen-carbon dioxide transport studies. In particular, one of these liquids, FX-80, has been successfully employed to ventilate the lungs of various adult species for periods of up to $8 \mathrm{hr}(14)$. The effect of fluorocarbon liquid ventilation on pulmonary gas exchange $(10,17)$, surfaceactive properties (15), function $(10,21,24,27)$, and structure (19) has been studied previously. In addition, in order to pave the way for clinical applications, long term experiments have been conducted looking for residual fluorocarbon as well as morphologic, biochemical, and/or histologic evidence of toxicity after ventilation with fluorocarbon liquid $(11,16)$.

The premature lamb has been employed by various investigators as a model for studying many physiologic functions related to the human newborn $(4,5,18,28)$. Measurements of pulmonary mechanics and acid-base balance in this animal (26) during the first few hours of life indicate decreased lung compliance, increased respiratory rate, vascular shunting, and increased work of breathing similar to the preterm human neonate with respiratory distress (1). Because of pulmonary immaturity, these animals were not only difficult to ventilate, but also hard to keep alive. The purpose of the present study was to evaluate the feasibility and efficacy of liquid ventilation as a therapeutic method in this animal model. Pulmonary gas exchange, acid-base balance, and inflation pressures were measured in these animals during the first few hours of life (a critical time of biologic instability). Results of this study were compared with previous measurements performed during gas ventilation studies conducted in the same distressed animal model at similar ages (26).

\section{METHODS}

The experiments were conducted using a previously described but modified liquid breathing system (25). As seen in Figure 1, the system consists of two electrically triggered bellows pumps used to deliver and remove the fluorocarbon liquid from both the regenerator of the system and the lungs of the animals. Oxygenation of the liquid and removal of carbon dioxide from the liquid were performed by bubbling $100 \%$ oxygen into the base of the regenerator, which was filled with fluorocarbon. The temperature of the liquid was maintained at $40^{\circ}$ using an electrically controlled temperature regulator and heater. Solenoid and check valves restricted fluid flow in the desired directions. Tidal volume and frequency were controlled by an electronic system actuator and controller. To measure the change in the animals's weight, a strain gauge platform was employed. This was necessary to monitor accurately both tidal volume and functional residual capacity, and was accurate to within $\pm 2 \mathrm{ml}$ of fluorocarbon liquid.

Nine premature lambs ranging in gestational age from 135-138 days and weighing 1.31-3.64 kg were delivered by cesarean section under epidural anesthesia with Carbocaine $1.5 \%$. After the uterus had been opened sufficiently for the head of the lamb to emerge, a rubber glove containing warmed saline solution was placed over the head of the fetus to prevent inspiration of gas. A carotid artery and a jugular vein were cannulated before delivery of the animal, and an arterial blood specimen $(0.5 \mathrm{ml})$ was taken for blood gas analysis. A tracheal cannula was inserted midway along the trachea, with its tip positioned proximal to the carina. After aspiration of lung fluid from the trachea, the rubber glove was removed from the animal's head, and the animal was delivered. The umbilical cord was then clamped, and $10 \mathrm{ml} 7.5 \%$ sodium bicarbonate and $10 \mathrm{ml} 10 \%$ glucose water were administered intravenously. The newly born lamb was weighed, wiped, dried, and placed under a heat lamp to maintain a neutral thermal state, during which time the tracheostomy tube was connected to a volume-controlled piston pump (Harvard small animal respirator).

Each lamb was hyperventilated with $100 \%$ oxygen for a control period of 15-20 min before the initiation of liquid breathing (this was to remove nitrogen from the body, elevate oxygen, and depress carbon dioxide tensions in the blood). 


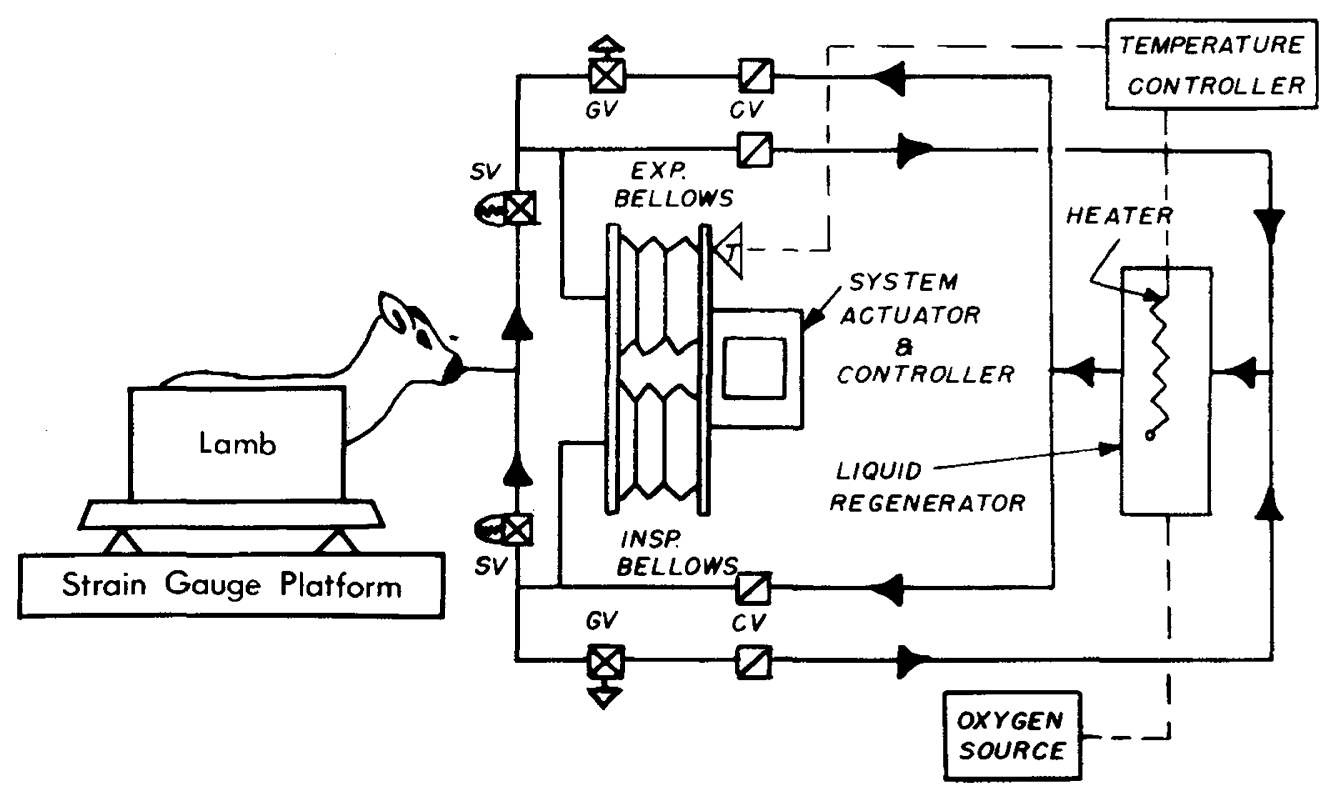

Fig. 1. A schematic of experimental set-up. $S V$ : solenoid values; $G V$ : gate valves; $C V$ : check values.

Warmed, oxygenated liquid was initially removed from the liquid breathing system and placed in a suspended reservoir. A volume equivalent to the functional residual capacity of the lungs was instilled from this reservoir via the tracheostomy tube into the animal's lungs. Postural and thoracic manipulations were performed to force out any large pockets of oxygen which might have become trapped in the lungs after instillation of the liquid. Such gas was free to escape into the reservoir, rather than into the gas-free liquid breathing system. Since the animal was previously hyperventilated with $100 \%$ oxygen, it is assumed that all gas remaining in the lungs is oxygen, which is either absorbed by the liquid or utilized by animal metabolism. Very few bubbles of gas were observed through the clear polyvinylchloride tracheostomy tube.

Arterial blood gases were drawn through the carotid artery catheter at 15-min intervals. Concomitant with sampling of the arterial blood, the $\mathrm{pO}_{2}$, and $\mathrm{pCO}_{2}$ of the fluorocarbon liquid were measured, on inspiration, at the point of entry of the fluid into the tracheostomy tube. Through the venous catheter, an infusion of $10 \%$ glucose in $1 / 8$ normal sodium bicarbonate was administered at a rate consistent with maintenance fluid therapy for the animal. Additional sodium bicarbonate was administered intravenously as needed in an attempt to correct ongoing metabolic acidosis (2).

The animal's tidal volume and functional residual capacity were closely monitored using the previously described strain gauge platform. Inspiratory and expiratory flow rates were adjusted to compensate for changes in functional residual capacity. In addition, a thermocouple was inserted into the rectum of the animal for constant monitoring of body temperature.

After each animal had been maintained on the liquid breathing system (eight lambs for $1 \mathrm{hr}$; one lamb for $3 \mathrm{hr}$ ) the fluorcarbon was emptied from the lungs and airways by inverting the animal. Using postural and thoracic manipulations, a volume of liquid approximately equivalent to that instilled was collected by free flow. At this time, the recovery phase, the animal was reconnected to the gas ventilator in an ambient oxygen concentration of $100 \%$. During this 20 min period, the tidal volume and respiratory rate settings were identical with those of the control period.

From previous studies (26) it was found that premature lambs of 135 days of gestation require either oxygen therapy or ventilatory support for survival. Although it would have been possible to maintain animals in this manner, this was not the purpose of the experiment. Therefore, animals were killed after the recovery phase.

\section{RESULTS}

As expected, all animals exhibited some degree of extrapulmonary shunting: (6) during the control ventilation period on gas, utilizing $100 \%$ oxygen as the ventilating medium. This was because of the cardiopulomnary instability characteristic of the premature animal, and is manifested by achievement of a mean arterial $\mathrm{PO}_{2}$ of $390 \pm 37 \mathrm{~mm} \mathrm{Hg} \mathrm{SE}$. with an inspired $\mathrm{PO}_{2}$ of $713 \mathrm{~mm} \mathrm{Hg}$ (Fig. 2). Hyperventilation during the control period was achieved with a tidal volume ranging from $22-35 \mathrm{ml}$ and respiratory rates ranging from $25-30$ breaths/min.

While on the liquid breathing system, ventilation was achieved with a tidal volume ranging from $28-56 \mathrm{ml}$ and respiratory rates ranging from $9-15$ breaths $/ \mathrm{min}$. The mean arterial $\mathrm{PO}_{2}$ was within the range of $175-200 \mathrm{~mm} \mathrm{Hg}$ while the animal was ventilated with the liquid breathing system. Note that the quantitative diminution in arterial $\mathrm{PO}_{2}$ approximately equals the adjusted decrease in $\mathrm{PO}_{2}$ of the ventilatory medium (inspired liquid) of approximately $200 \mathrm{~mm} \mathrm{Hg}$.

Figure 3 represents measured changes in $\mathrm{pH}$ and $\mathrm{pCO}_{2}$ and calculated changes in bicarbonate concentration before, during, and after liquid breathing. It can be seen that hyperventilation with the gas ventilator was readily achieved, with a mean arterial $\mathrm{pCO}_{2}$ of $22.0 \pm 1.45 \mathrm{~mm} \mathrm{Hg} \mathrm{SE}$. The mean arterial $\mathrm{pH}$ observed during the control phase did not rise higher than 7.46 because of a concomitant metabolic acidosis, not totally corrected by the initial administration of sodium bicarbonate.

Over the $1 \mathrm{hr}$ of liquid ventilation, the mean arterial $\mathrm{pCO}_{2}$ remained in the range of $38-4.1 \mathrm{~mm} \mathrm{Hg}$ and the mean arterial $\mathrm{pH}$, 7.31-7.35. During the recovery phase, hyperventilation was again easily accomplished, and there was no statistically significant difference between control phase and recovery phase values of $\mathrm{PCO}_{2}$. Minute ventilation was identical in each animal's control and recovery periods. In addition, as previously shown in Figure 2, the mean arterial $\mathrm{PO}_{2}$ rose to $319 \pm 32 \mathrm{SE} \mathrm{mm} \mathrm{Hg}$ after resumption of gas, ventilation with $100 \%$ oxygen. The difference between the mean arterial $\mathrm{PO}_{2}$ values observed in the control and recovery phases may be explained by a reduction in alveolar $\mathrm{pO}_{2}$, because of the additional vapor pressure of the residual fluorocarbon $\left(57 \mathrm{~mm} \mathrm{Hg}\right.$ at $37^{\circ}$ ) remaining in the lung after liquid ventilation.

Figure 4 represents the mean $\pm \mathrm{SE}$ rectal temperature of all animals before and during liquid breathing. As can be seen, the animals' core temperature may be easily maintained by controlling 


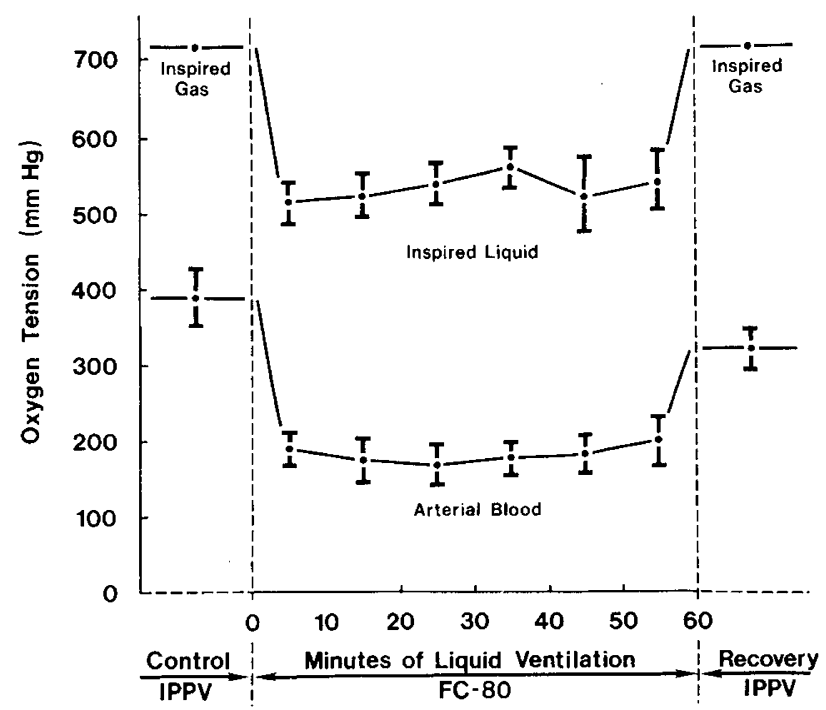

Fig. 2. Oxygen tension of inspired gas, liquid, and arterial blood for eight premature lambs before, during, and after liquid ventilation (mean $\pm \mathrm{SE}$ ). $I P P V$ : intermittent positive pressure ventilations.
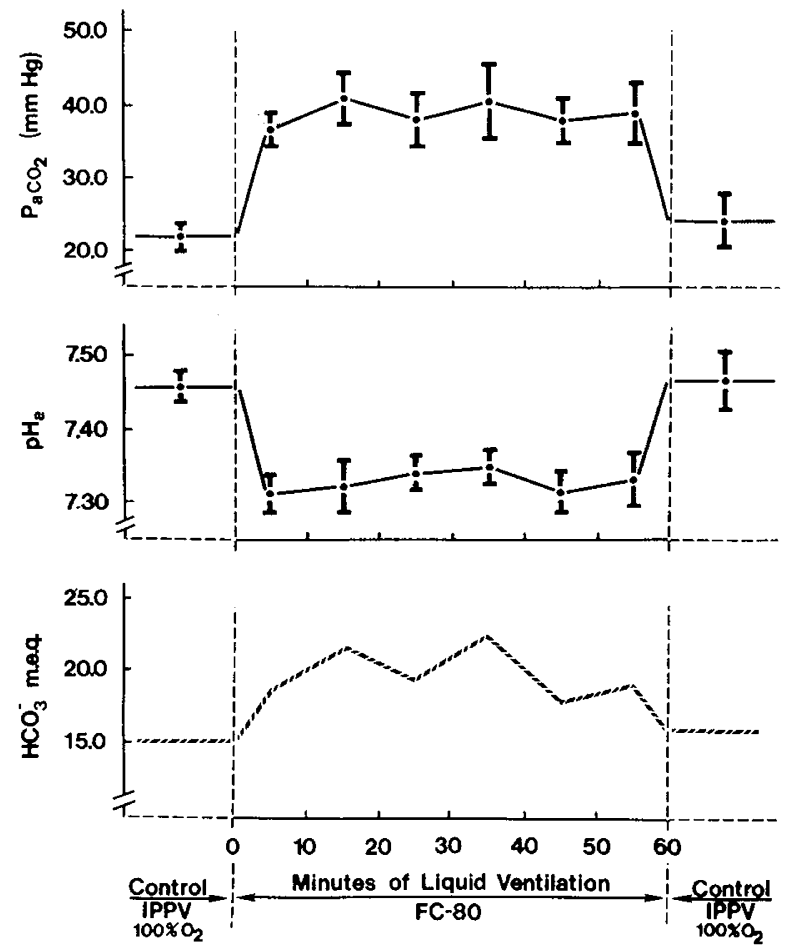

Fig. 3. Arterial $\mathrm{PCO}_{2}, \mathrm{pH}$, and $\mathrm{HCO}_{3}$ for eight premature lambs before, during, and after liquid ventilation (mean $\pm \mathrm{SE}$ ). IPPV: intermittent positive pressure ventilation.

the temperature of the ventilating liquid. The heat lamp used to maintain the animals' temperature while on the gas ventilator became superfluous once the animals were transferred to the liquid breathing system. At an average liquid temperature of $40^{\circ}$, the animals' core temperatures were for the most part above $38^{\circ}$. This easy maintenance of body temperature is due to the tremendous surface area in the lung available not only for gas diffusion, but also for heat exchange.

It became obvious during the course of the study that peak intratracheal pressure decreased markedly during the recovery period when compared with the control periods. Although this was noted in the first few animals, it was, unfortunately, not recorded. Subsequent animals were measured and recorded in Table 1. Note that for the same tidal volume and respiratory rates peak intratracheal pressure decreased significantly $(P<0.001)$ after liquid ventilation. This decrease in peak intratracheal pressure suggests improved compliance and surface properties of the lung.

One animal was maintained on the liquid breathing system for 3 hr and followed for 2 more hours during the recovery period. As seen in Figure 5, gas exchange and acid-base balance was remarkably stable during the $3 \mathrm{hr}$ of liquid ventilation and similar to the eight animals ventilated for $1 \mathrm{hr}$. It was also found that during the recovery period, peak intratracheal pressure was reduced $\left.13 \mathrm{~cm} \mathrm{H}_{2} \mathrm{O}\right)(32 \%)$ for the same ventilation rate and tidal volume as compared with the control period. This result persisted for the $2 \mathrm{hr}$ of the recovery phase, and is similar to that found in the six other lambs (Table 1).

In this study it was found that premature lambs were successfully oxygenated and mechanically ventilated with fluorocarbon liquid (FC-80) for periods of up to $3 \mathrm{hr}$. The mechanical liquid breathing system developed by our group (25) effectively provided tidal volumes and respiratory rates appropriate for animal size and age.

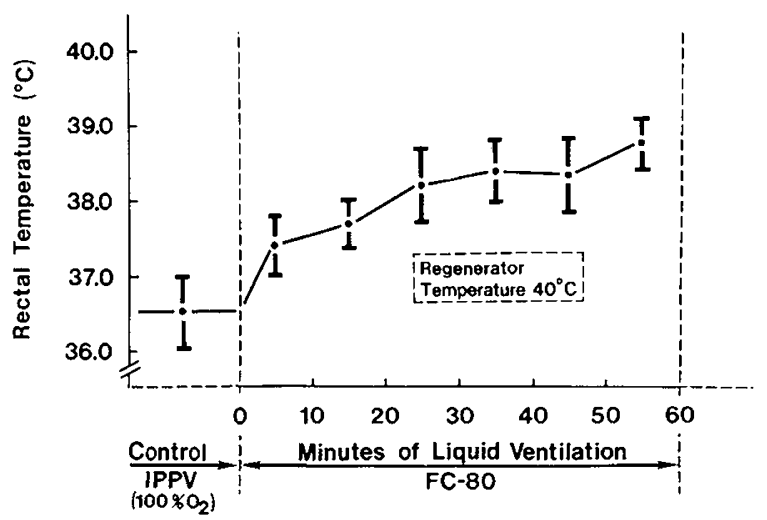

Fig. 4. Rectal temperatures of eight premature lambs before and during liquid ventilation (mean $\pm \mathrm{SE}$ ). IPPV: intermittent positive pressure ventilation.
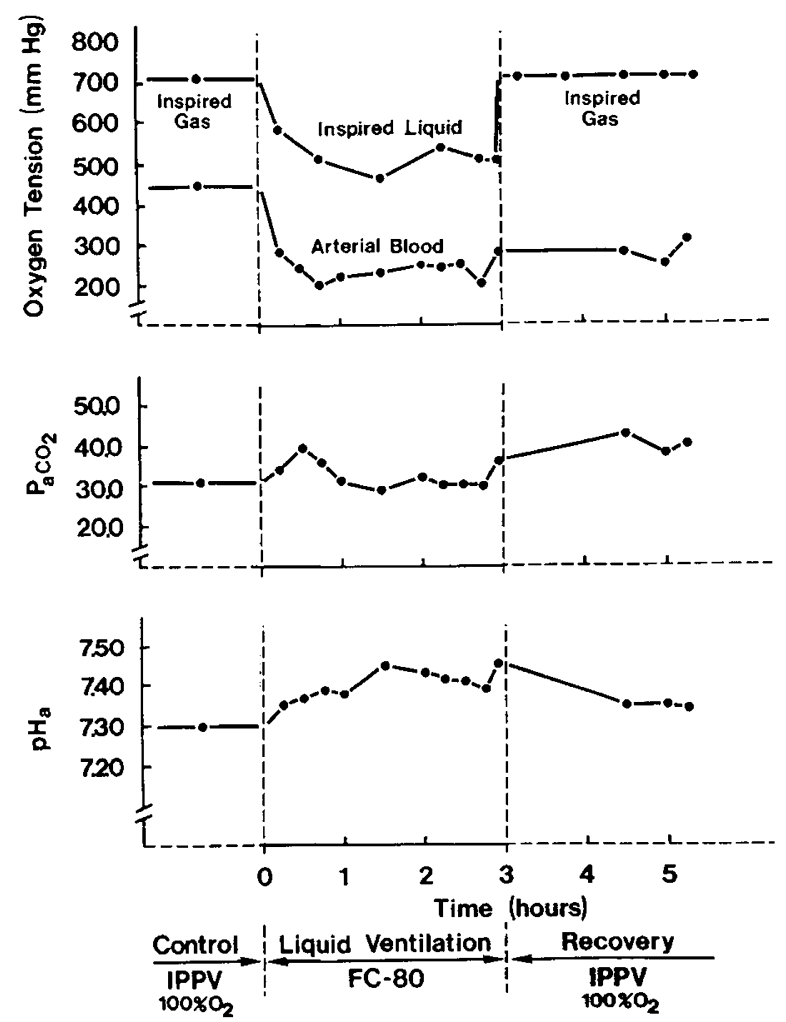

Fig. 5. Measurements made in one premature lamb during $100 \%$ intermittent positive pressure ventilation (IPPV), $3 \mathrm{hr}$ of liquid ventilation, and $2 \mathrm{hr}$ of recovery with $100 \%$ IPPV. 
Table 1. Peak intratracheal pressures in six premature lambs ventilated with $15 \mathrm{ml}$ gaseous oxygen tidal volume $/ \mathrm{kg}$ body weight before and after $1 \mathrm{hr}$ of liquid ventilation ${ }^{1}$

Peak intratracheal pressures, $\mathrm{cm} \mathrm{H}_{2} \mathrm{O}$

\begin{tabular}{ccc}
\cline { 2 - 3 } Lamb & Preliquid & Postliquid \\
\hline 3 & 35 & 20 \\
4 & 45 & 30 \\
5 & 35 & 22 \\
6 & 45 & 35 \\
7 & 35 & 25 \\
8 & 22 & 18 \\
\hline
\end{tabular}

${ }^{1} P<0.001$.

The oxygen tensions during the liquid ventilation (Fig. 2) were consistently maintained in a physiologic range appropriate for the degree of vascular shunting and inspired oxygen tension in contrast to previous liquid ventilation studies $(3,10,13,14,20)$ in both adults and newborn animals. In recent studies (26) we found that premature lambs mechanically ventilated since birth with gas demonstrated a large variation in pulmonary mechanics manifested by a great deal of variability in arterial blood gases. In contrast, all eight lambs ventilated with oxygenated fluorocarbon exhibited a relatively constant $\mathrm{paO}_{2}$ and $\mathrm{paCO}_{2}$ during $1 \mathrm{hr}$ of liquid ventilation, with no statistical variation during this period of time.

Carbon dioxide retention has been frequently reported in the literature $(3,10,13,14)$ as one of the major problems associated with normothermic liquid ventilation. However, in the present study, $\mathrm{CO}_{2}$ was effectively eliminated from all animals and subsequent arterial tensions were maintained at normal or low levels (Fig. 3).

There are several factors which may have contributed to the improvement of $\mathrm{CO}_{2}$ elimination. Unlike previous methods of liquid delivery, the present system provides both active delivery and removal of liquid from the lungs which probably results in better mixing of alveolar liquid. Ventilation was achieved with appropriately small tidal volumes of $28-56 \mathrm{ml}$ and breathing rates of $9-15$ breaths/min. In addition, the closed circuit liquid breathing system provided almost complete removal of $\mathrm{CO}_{2}$ from expired FC-80 liquid in the system regenerator. Finally, since the premature lamb has never been employed for liquid ventilation experiments previously, one cannot be certain of some inherent species difference (i.e., metabolic, structural, functional, etc.).

The buffer base in spite of constant bicarbonate infusion was slightly decreased, reflecting a persistent mild metabolic acidosis (Fig. 3). Sass et al. (23) have suggested that acidemia during liquid ventilation is due to the decreased buffering capacity of the blood. In addition, he has speculated that both the acidemia and loss of buffering capacity may have resulted from prolonged high arterial $\mathrm{pO}_{2}$ as described by Gesell (9). Whether this persistent acidosis was due to loss of buffering capacity, high oxygen tensions, cardiac output adjustments, or regional blood flow distribution is not clearly understood at the present time.

Premature mammals typically display an instability of temperature control at birth. There is a relatively large heat loss from the body because of evaporation of surface liquid and excess radiation of body heat, secondary to the high ratio of surface area to body weight characteristic of the premature. By employing the heating capacity of the liquid breathing system, it was possible to restore and control animal body temperature $(8)$ in a safe physiologic range (Fig. 4). Since the surface area of the newborn lung (7) is an order of magnitude greater than the surface area of the body, heat transfer can be accomplished more rapidly and efficiently.

Rufer and Spitzer (20) reported in 1974 that flushing the immature lungs of mini-pigs with fluorocarbon liquid resulted in an improvement of pressure volume curves approaching that of a mature lung. In the present series, we found a significant decrease in peak intratracheal pressure after $1 \mathrm{hr}$ of liquid ventilation (Table 1). In addition, one lamb was ventilated for $3 \mathrm{hr}$ on liquid and studied for several hours during recovery. During the recovery period it was found that peak intratracheal pressure was reduced from 40 (preliquid) to $27 \mathrm{~cm} \mathrm{H}_{2} \mathrm{O}$ (postliquid). These results indicate that an improvement in lung compliance can be demonstrated after several hours of liquid ventilation and that this improvement is not short lived. Alterations in lung function of the premature animal are in direct contrast to that of the adult animal previously reported by our group (24) and by other investigators $(21,27)$.

In recent studies with premature lambs ventilated since birth with a mechanical (gas) respirator, we found that lung mechanics varied greatly during the first several hours postnatally. These results indicated that the lung of the premature lamb was highly unstable with continuously changing pulmonary function values (26). The fact that all liquid-ventilated lambs showed evidence of improved stable lung function suggests that fluorocarbon liquid or liquid per se has a beneficial effect on the surface tension properties of the immature alveoli. This effect is probably due to the low surface tension FC-80 (15 dynes/cm) remaining in the lung after recovery from liquid ventilation.

\section{SUMMARY}

In conclusion, the results of this study indicate that liquid ventilation is an effective therapeutic method for ventilating distressed premature lambs during a period of biologic instability. This method not only provides adequate gas exchange and evidence for a reduction in surface active forces (1) during liquid breathing, but also demonstrates a subsequent reduction in inflation pressures following liquid ventilation (comparison of preand postliquid values, Table 1).

\section{REFERENCES AND NOTES}

1. Avery, M. E., and Fletcher, B. D.: The Lung and Its Disorders in the Newborn Infant (W. B. Saunders Co., Philadelphia, 1974).

2. Behrman, R.: The use of acid-base measurements in the clinical evaluation and treatment of the sick neonate. J. Pediat. 74: 632 (1969).

3. Clark, L. C., and Gollan, F.: Survival of mammals breathing organic liquid equilibrated with oxygen at atmospheric pressure. Science, 152: 1755 (1966).

4. Cook, C. D., Drinker, P.A., Jacobson, H. N., Levison, H., and Strang, L. B.: Control of pulmonary blood flow in the fetal and newly born lamb. J. Physiol., 169: 10 (1963).

5. Dawes, G. S., Mott, J. C., Widdicombe, J. G., and Wyatt, D. G.: Changes in the lungs of the newborn lamb. J. Physiol., I21: 141 (1953).

6. Dawes, G. S.: Foetal and Neonatal Physiology, pp. 151, 169 (Yearbook Medical Publishers, Inc., Chicago, 1968).

7. Dawes, G. S.: Foetal and Neonatal Physiology, p. 185 (Yearbook Medical Publishers, Inc., Chicago, 1968).

8. Dawes, G. S.: Foetal and Neonatal Physiology, p. 192 (Yearbook Medical Publishers, Chicago, 1968).

9. Gesell, R.: On the chemical regulation of respiration. I. The regulation of respiration with special reference to the metabolism of the respiratory center and the coordination of the dual function of hemoglobin. Amer. J. Physiol., 66: 5 (1923).

10. Gollan, F., McDermott, J., Johnson, A. C., and Namon, R.: Compliance and diffusion during respiration with fluorocarbon liquid. Fed. Proc., 29: 1725 (1970).

11. Holaday, D. A., and Modell, J. H.: Uptake and distribution in the dog of an inert fluorocarbon, FX-80. Fed. Proc., 29: 684 (1970).

12. Kylstra, J. A.: Lavage of the lung. Acta Physiol. Pharmacol. Neerl., 7: 163 (1958).

13. Kylstra, J. A., Paganelli, C. V., and Lanphier, E. H.: Pulmonary gas exchange in dogs ventilated with hyperbarically oxygenated liquid. J. Appl. Physiol., 21: 177 (1966).

14. Modell, J. H., Newly, E. J., and Ruiz, B. C.: Long term survival of dogs after breathing oxygenated fluorocarbon liquid. Fed. Proc., 29: 1737 (1970).

15. Modell, J. H., Gollan, F., Giammona, S. T., and Parker, A.: Effect of fluorocarbon liquid on surface tension properties of pulmonary surfactant. Dis. Chest, 57: 263 (1970).

16. Modell, J. G., Tham, M. K., Modell, J. H., Calderwood, H. W., and Ruiz, B. C.: Distribution and retention of fluorocarbon "ruid in mice and dogs after injection or liquid ventilation. Toxicol. Appl. ruarmacol., 26: 86 (1973).

17. Modell, J. H., Hood, C. I., Kuck, E. J., and Ruiz, B. C.: Oxygenation by ventilation with fluorocarbon liquid (FX-80). Anesthesiology, 34: 312 (1971).

18. Pagtakhan, R. D., Faridy, E.E., and Chernick, V.: Interaction between arterial 
$\mathrm{P}_{\mathrm{O}_{2}}$ and $\mathrm{P}_{\mathrm{CO} 2}$ in the initiation of respiration of fetal sheep. J. Appl. Physiol., 30 382 (9171).

19. Patel, M. J., Syanto, P., Yates, B., and Long, D. M.: Survival and histopathologic changes in lungs of hamsters following synthetic liquid breathing. Fed Proc., 29: 1740 (1970).

20. Rufer, R., and Spitzer, H. L.: Liquid ventilation in the respiratory distress syndrome. Chest, 66: 295 (1974).

21. Saga, S. J., Modell, J. H., Calderwood, H. W., Lucas, A. J., Tham, M. K., and Swenson, E. W.: Pulmonary function after ventilation with fluorocarbon liquid P-12F (CAroxin-F). J. Appl. Physiol., 34: 60 (1973).

22. Sargent, J. W., and Seffl, R. J.: Properties of perfluorinated liquids. Fed. Proc., 29: $1699(1970)$.

23. Sass, A. J., Wood, E. H., Greenleaf, J. F., Rittman, E. L., and Smith, H. C.: Effects of breathing liquid fluorocarbons on regional differences in pleural pressures and other physiological parameters (U.S.A.F. School of Aerospace Medicine, December, 1972).

24. Shaffer, T. H., and Moskowitz, G. D.: Demand-controlled liquid ventilation of the lungs. J. Appl. Physiol., 36: 208 (1974).

25. Shaffer, T. H., and Moskowitz, G. D.: An electromechanical demand regulated liquid breathing system. IEEE Trans. Biomed. Eng. 5: 412 (1975).
26. Shaffer, T. H., Arcinue, E., Paez, P., DuBois, A. B., and DelivoriaPapadopoulos, M. Variation of pulmonary mechanics and acid base balance in premature lambs during the first six hours of life. Fed. Proc., 34: 275 (1975).

27. Tuazon, J. G., Modell, J. H., Hood, C. I., and Swenson, E. W.: Pulmonary function after ventilation with fluorocarbon liquid (CAroxin-A). Anesthesia, 38: 134 (1973).

28. Zweizig, H. Z., Kuhl, D. E., Kutz, R., and Polgar, G.: Distribution of pulmonary blood flow in fetal and newborn lambs. Resp. Physiol., 8: 160 (1970).

29. The authors are grateful to Dr. Robert E. Forster for his valuable consultation and suggestions, and to Mr. Jonathan DeLong, Ms. Lee Gittens, and Ms. Monica Clossin for their technical assistance.

30. Drs. T. Shaffer and M. Delivoria-Papadopoulos were recipients of National Institutes of Health, Young Investigator Pulmonary Research Grant and Career Development Award, respectively.

31. The research leading to this paper was supported by the Public Health Service Grants nos. HC-17154, HD-07135, and HL-15061.

32. Requests for reprints should be addressed to: T. Shaffer, Ph.D., Department of Physiology, Medicine, and Pediatrics, School of Medicine, University of Pennsylvania, Philadelphia, Pa. 19174 (USA).

33. Accepted for publication November 17, 1975.

\title{
Lactate and Pyruvate as Fetal Metabolic Substrates
}

\author{
VALERIE CHARLTON CHAR ${ }^{(25)}$ AND ROBERT K. CREASY \\ Cardiovascular Research Institute and the Department of Obstetrics and Gynecology, University of \\ California at San Francisco, San Francisco, California, USA
}

\section{Extract}

Whole blood lactate, pyruvate, and oxygen concentrations were measured simultaneously in the umbilical vein, fetal femoral artery, maternal artery, and uterine vein in 14 chronically catheterized pregnant ewes and their fetuses. Lactate was found to be taken up in significant amounts across the placental circulation by the fetuses, whereas pyruvate was not.

The lactate concentration of fetal blood was higher than that of maternal blood; however, fetal lactate levels correlated with maternal arterial levels $(P \leq \mathbf{0 . 0 1})$. The mean lactate concentrations in all samples were: common umbilical vein, $2.105 \mathrm{mM}$; fetal femoral artery, $1.986 \mathrm{mM}$; and maternal artery, $0.823 \mathrm{mM}$. Where uterine venous lactate concentrations were measured, the lactate content of the uterine vein exceeded that of the maternal artery by a mean of $0.088 \mathrm{mmol} /$ liter $(P<\mathbf{0 . 0 0 5})$. The mean fetal gain in lactate across the placental circulation was $0.118 \mathrm{mmol} /$ liter $(P<0.005)$. This is equivalent to a gain of $1.2 \mathrm{~g}$ carbon $/ \mathrm{kg} / 24 \mathrm{hr}$ by the growing lamb fetus. The mean fraction of fetal oxygen consumption that could be accounted for by oxidation of lactate was 0.32 .

The pyruvate concentration of fetal blood was higher than that of maternal blood; however, fetal pyruvate levels correlated with maternal arterial levels $(P<\mathbf{0 . 0 5})$. The mean pyruvate concentrations in all samples were: common umbilical vein, $0.084 \mathrm{mM}$, fetal femoral artery, $0.094 \mathrm{mM}$; and maternal artery, 0.053 $\mathrm{mM}$. Where uterine venous pyruvate concentrations were measured, they exceeded the maternal arterial concentrations by a mean of $0.005 \mathrm{mmol} /$ liter $(P=0.001)$. Pyruvate appeared to be lost by the fetus across the placental circulation by a mean of 0.010 $\mathrm{mmol} /$ liter. This loss of pyruvate correlated with the placental fetal to maternal pyruvate concentration gradient $(P<0.05)$.
Correlations between maternal arterial and fetal lactate concentrations imply that fetal lactate levels are influenced by maternal levels. The increase in lactate concentration of both fetal and maternal blood during circulation through the placenta indicates placental production of lactate. The pyruvate concentrations observed, however, are consistent with either fetal to maternal flow of pyruvate or placental production.

\section{Speculation}

Lactate, after glucose and amino acids, is the third most important fetal substrate identified in the fetal lamb. Its role as a fetal fuel now needs to be evaluated in other animal species.

The pregnant sheep, surgically prepared with indwelling fetal and maternal catheters, is a useful animal model for studying fetal metabolism in an undisturbed physiologic state. With the use of this animal preparation glucose $(7,12)$, fructose (17), amino acids $(8,10)$ ketones $(13)$, glycerol, free fatty acids $(11,19)$ and acetate (6) have been investigated as possible fetal fuels. Of these substances only glucose, amino acids, and acetate have been shown to cross the placenta in significant amounts for use in fetal metabolism. Analyses of the carbon content of the lamb fetus and its waste products indicate that at least $7.69 \mathrm{~g}$ carbon $/ \mathrm{kg} / 24 \mathrm{hr}$ must be supplied to the fetus during the last one-third of gestation (2). Glucose, amino acids and acetate can account for only $77 \%$ of this carbon and their metabolism can account for, at most, $80 \%$ of the fetal oxygen consumption $(2,6,10,12)$. Additional substrates must therefore be used by the fetus in large amounts.

Lactate and pyruvate are fundamental intermediates in carbohy- 